\title{
The Analysis to Movement Patterns in Standing Up in Children with Spastic Hemiplegia
}

\section{문제강, 오태영'}

서울시 강북구 보건소, ${ }^{1}$ 신라대학교 물리치료학과

\author{
The Analysis to Movement Patterns in Standing Up in Children with Spastic Hemiplegia \\ Je-Kang Moon, PT, MS, Tae-Young Oh, PT, Ph.D ${ }^{1}$ \\ Dept. of Physical Therapy, Seoul Metropolitan Gang Buk-Gu Community Health Center \\ ${ }^{1}$ Dept. of Physical Therapy, Silla University
}

Purpose This study aimed to evaluate the strategical changes of movement patterns and measure the MSS(mean segmental score)of children with spastic hemiplegia according to age by observing the standing up movements of spastic hemiplegia children. Method We performed visual analysis on the segmental movement pattern during standing up movement from supine position of 8 normal children and 8 children with spastic hemiplegia. We used Mann-Whitney $U$ test to evaluate the changes in MSS analysis and motion patterns of upper limbs, axis, and lower limbs and the changes of motion strategy in relation to the changes of age in the two groups of children. Result The result are as follows; 1) There was significant difference in MSS analysis on "forward with rotation" of axial region between the two groups of children aged $4 \sim 7$ years $(\mathrm{p}<0.02)$. 2) There was significant difference in MSS analysis on "Narrow-based symmetric squat" of lower limbs between the two groups of children aged 4 7 years and 8 12 years $(\mathrm{p}<0.01)$. 3) The children with spastic hemiplegia were using more flexor muscles when changing posture, and significant increase of asymmetrical motion pattern was observed when supporting the upper and lower limbs regularly. Conclusion Through the approach in this study, we could obtain knowledge about the regularity of motion patterns of children with cerebral palsy and as a result we could easily recognize the characteristics of posture and motion of children with cerebral palsy.

Key words Spastic hemiplegia children, Movement patterns, Mean segmental score.

교신 저자 오태영, ohtaeyoung@silla.ac.kr

논문접수일 2011년 7월 25일

수정접수일 2011년 9월 2일

게재승인일 2011년 10 월 10 일

\section{I . Introduction}

Congenital spastic hemiplegia is the usual form of cerebral palsy which is caused during fetal or perinatal period (20th gestation week 28th day after birth), and occurs from unilateral cerebral cortex injury or white matter injury during premature or normal delivery. ${ }^{1,2}$ Particularly the capability to perform organized motion and to maintain posture is damaged and can be characterized by spastic hemiplegia and the affected children show delayed motor development. $3,4,5$ That is they use generalized motions rather than selective motions and they prefer to sit down sidewards and crawl with asymmetrical posture in prone position because of the postural instability of the pelvic bone. ${ }^{6}$ In addition, lots of physiologic energy is required to maintain standing posture and walk, and when standing still they tend to support more weight on the leg without motor damage. ${ }^{7,6}$

Standing up from supine position is a basic activity for daily living which is necessary for the functional independence of a person and is necessary for the maintenance of normal posture against the gravity. ${ }^{8}$ The moving pattern a child uses for standing up from supine position has been described in 
various articles, Mc Graw (1945) ${ }^{9}$ explained that a child uses 7 steps of moving patterns to stand up from supine position, whereas Green and Williams $(1992)^{10}$ described that a normal child uses 4 steps of moving patterns through righting reaction to stand up from supine position of which the 4 steps consist of rolling to change the posture to prone position, motion to sit, standing up with crawling posture, and standing right up. But McCoy and VanSant (1993)11 described that the child develops motor function like lifting head, rolling, crawling, and standing which are applied for standing up from supine position by connecting and combining theses movements. In addition, the capability to stand up from lying down is an important component for the physical independence of a person, and the child develops motor functions through moving patterns of lower and upper limbs and axis used during standing up. Particularly, the age at which the motions are performed symmetrically is around $4 \sim 5$ years and the rotation of axis during standing up has been described to decrease in the adulthood. Marsala and VanSant $(1998)^{12}$ used multi-segmental approach categorizing the motion of the child into movements of upper limb, axial region(head, body), and lower limb to describe the detailed combined moving pattern and described that the crossed developmental ratio of combined moving pattern enables easy analysis of quantitative changes among individuals and that it is a important component for the qualitative analysis of body movements.

The purpose of this study is to recognize the relation between age and MSS(mean segmental score) or moving pattern through continuos-movement-and-posture analysis on spastic hemiplegia children during standing up and we also ought to evaluate the strategical changes of moving patterns. In addition, to fulfill the purpose of our study, we described the motions using multi-segmental approach proposed by Marsala and VanSant (1998) ${ }^{12}$ as well as using MSS introduced by Mewasingh et al $(2002,2004) .{ }^{13,5}$

\section{Method}

\section{Study subject and study period}

\section{1) Study group}

This study was performed on 8 children ( 6 males, 2 females) with spastic hemiplegia who are receiving out-patient physical therapy in Seoul Metropolitan children's Hospital and the average age of the subjects were 5.25 years and 10.00 tears (Table 1). We chose subjects who had limitations on gross motor function but could walk independently without any assistance (gross motor function classification system level I, ${ }^{14,15}$ (Table 2), and the study period was from December 2009 until February 2010.

Table 1. The general characteristics, the majority of participants

\begin{tabular}{|c|c|c|c|c|c|}
\hline & \multicolumn{2}{|c|}{$\begin{array}{l}\text { spastic hemiplegia } \\
\text { groups }\end{array}$} & \multicolumn{2}{|c|}{$\begin{array}{l}\text { normal child } \\
\text { groups }\end{array}$} \\
\hline & & $4 \sim 7(n=4)$ & $8 \sim 12 \quad(n=4)$ & $4 \sim 7 \quad(n=4)$ & $8 \sim 12$ (n=4) \\
\hline age & (year) & $5.25 \pm 1.26$ & $10.00 \pm 1.83$ & $5.50 \pm 1.29$ & $9.75 \pm 1.71$ \\
\hline \multirow{2}{*}{ diagnosis } & $\begin{array}{c}\text { right } \\
\text { hemiplegia }\end{array}$ & 3 & 1 & & \\
\hline & $\begin{array}{c}\text { left } \\
\text { hemiplegia }\end{array}$ & 1 & 3 & & \\
\hline \multirow{2}{*}{ sex } & boy & 3 & 3 & 3 & 3 \\
\hline & girl & 1 & 1 & 1 & 1 \\
\hline
\end{tabular}

$\mathrm{M} \pm \mathrm{SD}$ M: Mean, SD: Standard deviation

Table 2. Gross Motor Fuction Classification System for Assessing Severity of Cerebral Palsy ${ }^{15}$

Level I - $\begin{aligned} & \text { walks without restrictions; limitations in more advanced } \\ & \text { gross motor skills } \\ & \text { Level II- }\end{aligned}$
$\begin{aligned} & \text { walks without assistives; limitations in walking outdoors } \\ & \text { and in the community }\end{aligned}$
LevelIII- $\begin{aligned} & \text { walks with assistive mobility devices; limitation in } \\ & \text { walking outdoors and in the community }\end{aligned}$
LevelIV- $\begin{aligned} & \text { self mobility with limitation; children are transported or } \\ & \text { use power mobility outdoors and in the community }\end{aligned}$
Level V- $\begin{aligned} & \text { self mobility is severely limited even with use of assistive } \\ & \text { technology }\end{aligned}$

\section{2) Control group}

The control group subjects were chosen among the relatives and children of physical therapists and language therapist, particularly those who demonstrated normal developments without any diseases. Total 8 children were selected (6 males, 2 females) and the average age of these children was 5.50 years and 9.75 years (Table 1).

\section{Study design and method}

\section{1) Study design}

This study performed vertical sectioned observation on the 
continuos-moving pattern of children with spastic hemiplegia and normal children during standing up from supine position.

\section{2) Study method}

This study was performed in physical therapy room in Seoul Metropolitan children's Hospital for 3 months. The performance of motion was verbally instructed to stand up quickly from supine position without any visual demonstration. In addition, each child performed 10 consecutive exercises with 1 2 times of interval and all children were standing by to perform the exercise on instructions and every child was recorded with one digital camera. The camera was placed 2 meters away from the center of the mat to record vertical sectioned image of the child. The recorded files were copied into a computer and checked via the monitor.

\section{Data analysis}

The examiner analyzed the movement performance of each individual children of the two groups of children via the computer monitor, and movement pattern category from Marsala and VanSant $(1998)^{12}$ was used for the analysis (Table 3).

To minimize observation bias from continues observation, we analyzed the movement pattern separately beginning from the classify of upper limb, classify axial region and finally the lower limb. For each trial, the score per body segment(upper limb, axial region, lower limb) was scored using MSS. ${ }^{13,5}$ Then we used SPSS 12.0 for statistical processing for analysis of total 480 standing movements of each child, which had been performed for 120 times repeating 4 movements of each time (Table 3). General characteristics of the two groups were processed using descriptive statistics and to evaluate the changes in movement patterns and movement strategy with

Table 3. Comparison of MSS according to age

\begin{tabular}{|c|c|c|c|c|}
\hline \multirow{2}{*}{ Movement categories } & \multicolumn{2}{|c|}{ Study group Age groups (years) } & \multicolumn{2}{|c|}{ Control group Age groups lyears) } \\
\hline & $4 \sim 7(n=4) \%$ & $8 \sim 12(n=4) \%$ & $4 \sim 7(n=4) \%$ & $8 \sim 12(n=4) \%$ \\
\hline \multicolumn{5}{|l|}{ Upper limb categories } \\
\hline 1. Push and reach to bilateral push & 20.0 & & 40.0 & \\
\hline 2. Push and reach & 62.5 & 42.5 & 42.5 & \\
\hline 3. Symmetric push & & 25.0 & 12.5 & 67.5 \\
\hline 4. Symmetric reach & & & 5.0 & \\
\hline 5. Push and reach followed by pushing on leg & & & & 32.5 \\
\hline 6. Push and reach to bilateral push followed by pushing on leg & 17.5 & 32.5 & & \\
\hline \multicolumn{5}{|l|}{ Axial region categories } \\
\hline 1. Full rotation with abdomen down & & 7.5 & & \\
\hline 2. Full rotation with abdomen up & & 20.0 & 20.0 & \\
\hline 3. Partial rotation & 22.5 & & 17.5 & 30.0 \\
\hline 4. Forward with rotation & 52.5 & 47.5 & & \\
\hline 5. Symmetric & 25.0 & 25.0 & 62.5 & 70.0 \\
\hline \multicolumn{5}{|l|}{ Lower limb categoires } \\
\hline \multicolumn{5}{|l|}{ 1. Pike } \\
\hline 2. Pike-jump to squat & 10.0 & & 12.5 & 17.5 \\
\hline 3. Kneel & & & 2.5 & \\
\hline 4. Jump to squat & & & 20.0 & \\
\hline 5. Half-kneel & 40.0 & 45.0 & 65.0 & \\
\hline 6. Asymmetric/wide-base squat & 50.0 & 55.0 & & 20.0 \\
\hline 7. Narrow-based symmetric squat & & & & 62.5 \\
\hline Total of MSS & 120 & 120 & 120 & 120 \\
\hline
\end{tabular}

Adapted from Marsala and VanSant.12 Movement patterns for the task of rising from a supine position to a standing one. 
aging, we used Mann-Whitney $U$ test. The level of significance was set to $\alpha=0.05$.

\section{Result}

\section{Upper limb pattern}

There were no significant differences between the two groups in upper limb pattern. However $62.5 \%$ of $4 \sim 7$ years old children with spastic hemiplegia and $42.5 \%$ of $8 \sim 12$ years old children with spastic hemiplegia were using asymmetrical "push and reach" most frequently, whereas $42.5 \%$ of $4 \sim 7$ year old normal children and $67.5 \%$ of $8 \sim 12$ years old children were using "symmetric push" dominantly (Table 3) (Figure 1).

\section{Axial region pattern}

Compared to normal children, the only significant difference of axial region pattern were present in $4 \sim 7$ years old spastic hemiplegia children $(5.25 \pm 5.50)$ presenting "forward with rotation" ( $\mathrm{p}<0.02)$ (Table 4). Though statistically insignificant, "symmetric pattern" was dominant in normal children which was present in $62.5 \%$ of $4 \sim 7$ years old children and $70.0 \%$ of $8 \sim 12$ years old children (Table 3) (Figure 1).

\section{Lower limb pattern}

There was significant difference in $4 \sim 7$ years old $(6.20 \pm 2.36)$ normal children and 8 12 years old $(6.20 \pm 2.36)$ normal children on lower limb pattern presenting "Narrow-based-symmetric squat" (p<0.01) (Table 4) (Table 5). However 40.0\% of 4 7 years old children with spastic hemiplegia, $45 \%$ of $8 \sim 12$ years old children with hemiplegia, and $65 \%$ of $4 \sim 7$ years old normal children presented "half-kneel" but without significance. In addition, $50.0 \%$ of $4 \sim 7$ years old children with spastic hemiplegia and $55 \%$ of $8 \sim 12$ years old children with hemiplegia used "asymmetric/wide-base squat" dominantly (Table 3) (Figure 1).

\section{Discussion}

This study was designed to evaluate the characteristics and differences of movement pattern of children with spastic

Table 4. Comparison of MSS in 4 7 year old children

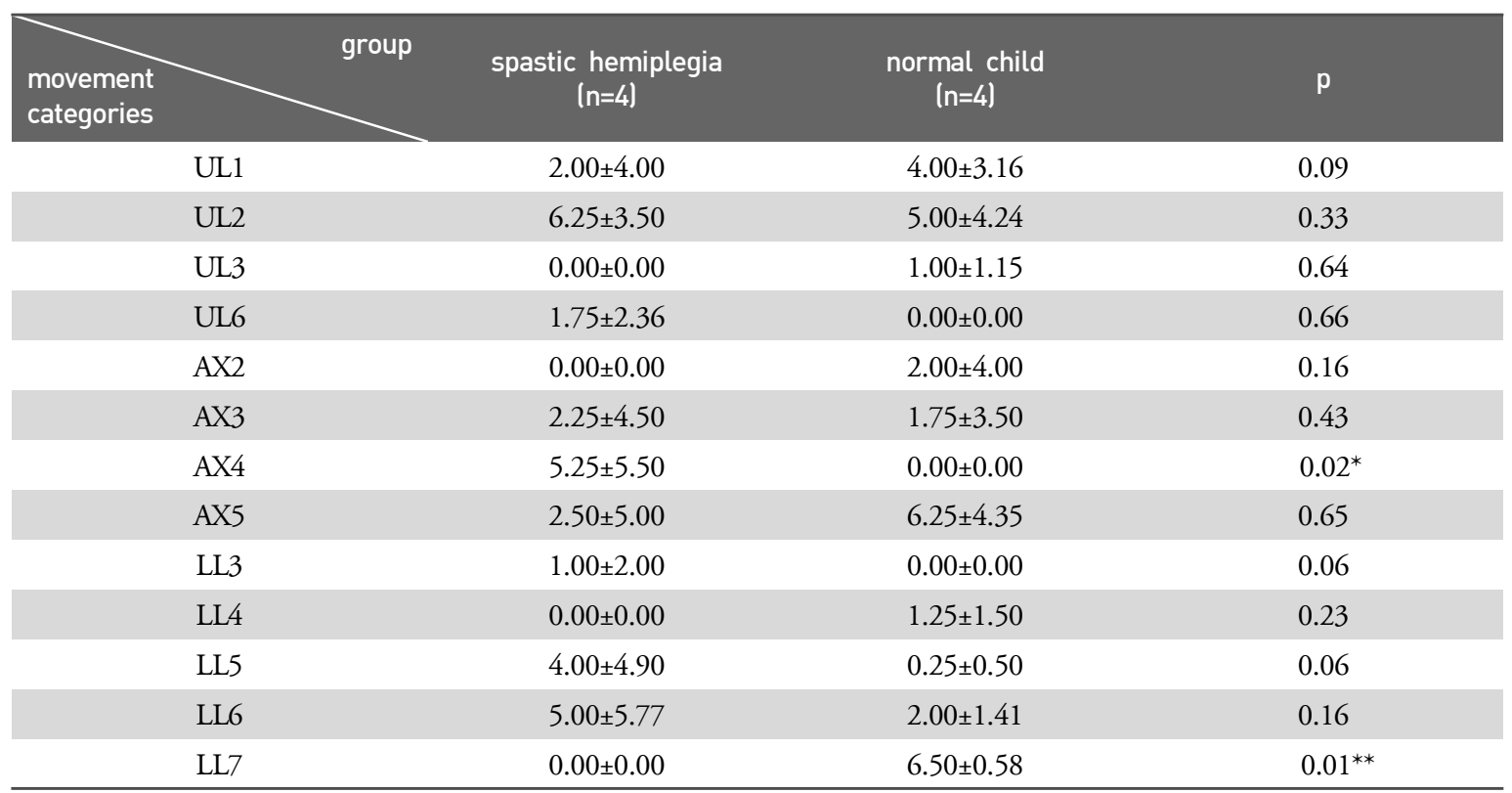

$\mathrm{M} \pm \mathrm{SD} * \mathrm{P}<0.05 * * \mathrm{P}<0.01$

UL1: Upper limb categories1 UL2: Upper limb categories2 UL3: Upper limb categories3

UL4: Upper limb categories4. UL5: Upper limb categories5 UL6: Upper limb categories 6

AX1: Axial categories1 AX2: Axial categories2: AX3: Axial categories3 AX4: Axial categories4

AX5: Axial categories5 LL1: Lower limb categoires1 LL2: Lower limb categoires2 LL3: Lower limb categoires3

LL4: Lower limb categoires4 LL5: Lower limb categoires5 LL6: Lower limb categoires6 LL7: Lower limb categoires7 
A
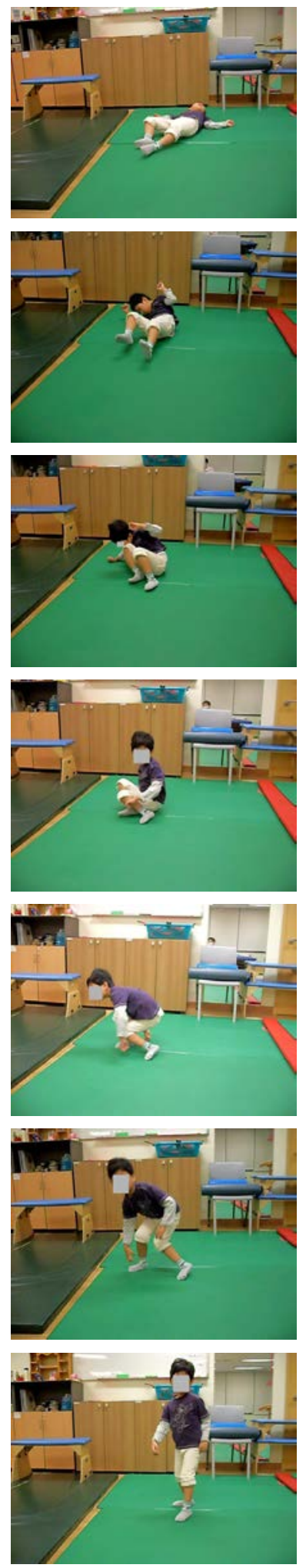
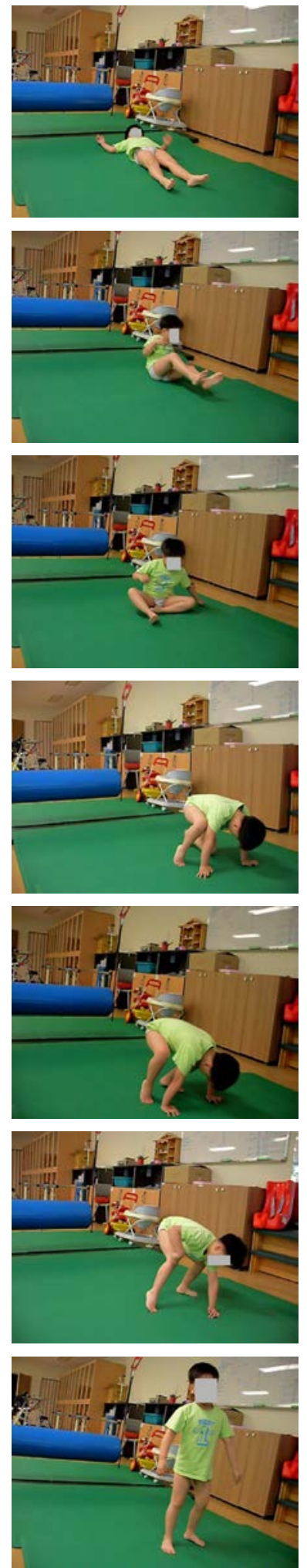

Figure 1. Standing up from a supine position in spastic hemiplegia:

(A) Six-year-old boy using "push and reach" UL pattern, "asymmetric/wide-based squat LL pattern.

(B) Nine-year-old boy using "forward with rotation" AX pattern, "asymmetric/wide-based LL patttern. 
Table 5. Comparison of MSS in 8 12 year old children

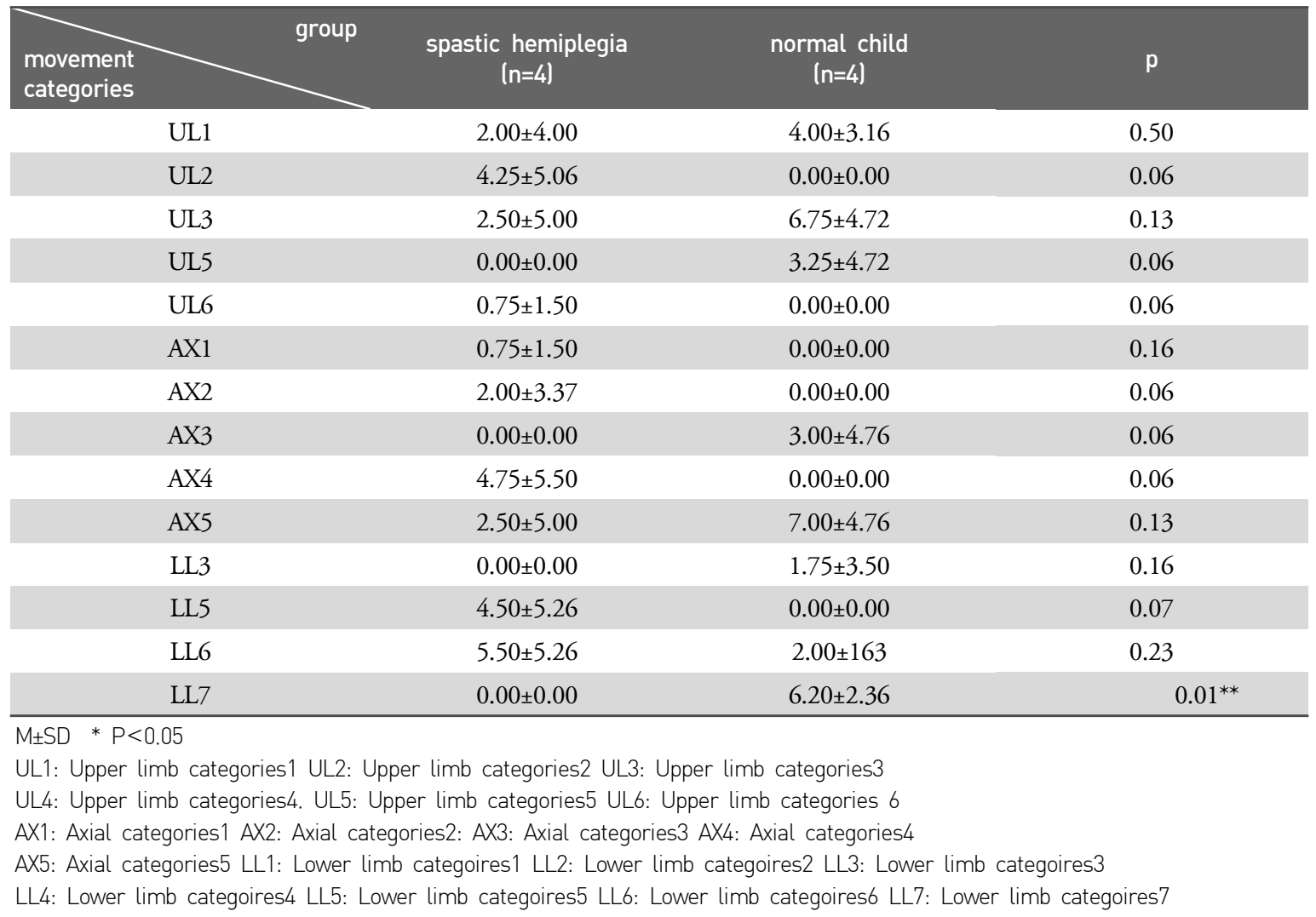

hemiplegia and normal children during standing up motion from supine position. ${ }^{12}$ In addition, we compared the movement pattern and movement strategy in different age groups by dividing the children into two groups of $4 \sim 7$ years old children and $8 \sim 12$ years old children.

First there was no significant difference on upper limb pattern between the two groups of children. However children with spastic hemiplegia were using "push and reach" dominantly (62.5\%) whereas normal children used "symmetric pattern" dominantly (67.5\%) (Table 3). Such result was similar to those of Mewasingh et al $(2004)^{5}$ and $\operatorname{VanSant}(1988)^{16}$ and Mewasingh et al $(2002)^{13}$ which demonstrated that the asymmetric "push and reach" was present in over 65\% in children with spastic hemiplegia and that the symmetric pattern was dominant in normal children. But our result was different form that of VanSant $(1990)^{17}$ which demonstrated that the normal children used two movement patterns of "Push and reach to bilateral push followed by pushing on leg" and "Push and reach followed by pushing on leg".
In axial region pattern, the children with spastic hemiplegia showed significant difference $(\mathrm{p}<0.02)$ (Table 4) in "forward with rotation" which is similar to the result of the study from Mewasingh et al (2004) $)^{5}$ which showed that $55 \%$ of children with spastic hemiplegia used "forward with rotation" pattern $(\mathrm{p}<0.001)$. Meanwhile, $62.5 \%$ of $4 \sim 7$ years old normal children and $70 \%$ of $8 \sim 12$ years old normal children used "symmetric" pattern dominantly but the difference was statistically insignificant (Table 3). Likewise, VanSant $(1988)^{18}$ described that adults use flexor muscles symmetrically to take a straight posture and that such "symmetric" pattern of standing up becomes more dominant during the process of development which may differ according to the dominance of body movement direction. In addition, Park et al $(2003)^{6}$ reported that postural change from supine position to standing-up becomes possible by the stabilization activity of body during the continuos adaptation process of a normal child. Moreover Full and Koditschek (1999) ${ }^{19}$ described that the men simplifies the motions and balance control with aging and that the men 
rises up as one large unit with stable form like horizontal or vertical plane. However Full and Koditschek $(1999)^{19}$ described that a child with spastic hemiplegia has more difficulties on orientating response, and that such restrictions in physical capability derives from complex reasosns like the difficulty of interaction between organisms, limited dynamic features on nonlinearity (not linear), and difference of intellectual level.

In lower limb pattern, 4 7 years old normal children and $8 \sim 12$ years old normal children used "narrow-based symmetric squat" with significant difference $(\mathrm{p}<0.01)$ (Table 4) (Table 5). However such result was different from the literature of Marsala and VanSant $(1998)^{12}$ which described that a $4 \sim 7$ years old normal child rotates the hip flexors and knee flexors internally and squats asymmetrically during hip rotation eventually rising on the larger basal surface when standing up from the supine position.

However, 4 7 years old and 8 12 years old children with spastic hemiplegia used "half-kneel" and "asymmetric/ wide squat" dominantly (Table 3). Such result is concordant with that of Mewasingh et al (2002) ${ }^{13}$ and Mewasingh et al $(2004)^{5}$ which showed that over $75 \%$ of children with spastic diplegia used "half-kneel" and "asymmetric/wide base squat" dominantly.

Features associated with movements for balance maintenance was more remarkable in children with hemiplegia. Children with spastic hemiplegia used flexor muscles more and asymmetric motion pattern was prominent on upper and lower limbs when using the unaffected side. Thus they could partially solve the problems of hypertonic, joint locking, and spasticity during whole body movements and balance maintenance using the multi-segmental movements. And the approach using movement analysis through symmetric harmonious body movements during righting and body control can be useful for physical therapy and occupational therapy for children with cerebral palsy.

The limitations of this study is that it can not be generalized to children with other forms of cerebral palsy because we performed our study only on children with spastic hemiplegia. Therefore further studies on children with various forms of cerebral palsy would be required to apply the results for children with various forms of cerebral palsy.

\section{Conclusion}

This study visualized the MSS patterns and strategical changes of movement patterns according to age by observing the movement patterns of 8 normal children and 8 children with spastic hemiplegia when standing-up from supine position. The result is as follows.

(1) There was significant difference in "forward with rotation" of axial region between the two groups of $4 \sim 7$ years old children $(\mathrm{p}<0.02)$.

(2) There was significant difference in "narrow-based symmetric squat" of lower limb between the two groups of $4 \sim 7$ years old and $8 \sim 12$ years old children $(\mathrm{p}<0.01)$.

(3) In comparison to normal children, children with spastic hemiplegia used more flexor muscles when maintaining posture and asymmetric movement pattern increased significantly in upper and lower limbs when supporting the unaffected side regularly.

Through our analytic approach, we could recognize the regularity of movement and posture of children with cerebral palsy and the characteristics of postural and motional regulation.

\section{References}

1. Aneja S. Evaluation of a child with cerebral palsy. Indian Journal of Pediatrics, Volume 71-jury, 2004.

2. Bobath B, Bobath K. Motor development in the different types of cerebral palsy. London: Heinemann Medical Books. 1975:42-57.

3. Cogher L, Savage E, Smith MF. Cerebral palsy the child and young person. Chapman \& Hall medical, London, 1992; 3-24.

4. Full RJ, Kodistschek DE. Templates and anchors: neuromechanical hypotheses of legged locomotion on land. The Journal of Experimental Biology 202, 1999;3325-3332.

5. Green LN, Williams K. Difference in developmental movement patterns used by active versus sedentary middle-age adults coming from a supine position to Erect stance. Phys Ther 1992:560-568.

6. Marsala G, VanSant AF. Age-related differences in movement patterns used by toddlers to rise from a supine position to erect stance. Phys Ther 1998;78:149-159.

7. McCoy JO, VanSant AF. Movement patterns of adolescents 
rising from a bed. Phys Ther 1993;73:182-192.

8. McGraw MB. The Neuromuscular maturation of the human infant. New York, NY, Hafner Press, 1945; 85-99.

9. Mewasingh LD, Demil A, Florence JC, Missa AM, Cheron G, Dan B. Motor strategies in standing up in leukomalacic spastic diplegia. Brain \& Development 2002; 24:291-295.

10. Mewasingh LD, Sekhara T, Pelc K, Missa AM, Cheron G, Dan B. Motor strategies in standing up in children with hemiplegia. by elsevier inc, alll rights reserved, 2004.

11. Palisano R, Rosenbaum P, Walter S, Russell D, Wood E, Galuppi B. Development and reliability of a system to classify gross motor function in children with cerebral palsy. Developmental Medicine \& Child Neurology 1997,39:214- 223.

12. Park ES, Park C, Lee HJ, Kim DY, Lee DS, Cho SR. The characteristics of sit-to-stand transfer in young children with spastic cerebral palsy based on kinematic and kinetic data. gait and posture 2003;17:43-9.

13. Schmidt RA. Motor control and learning : A behavioral emphasis, 2nd ed. 1988. Human Kinetics Publ, Inc, USA.

14. Scrutton D, Gilbertson M. Physiotherapy in paediatric practice. butterworth \& co(Publishers)Ltd, London and boston, 1975;48-49.

15. VanSant Ann F. Age differences in movement pattern used by children to rise from a supine position to erect stance. Phys Ther 1988;68:1330-1338.

16. VanSant Ann F. Life-span development in functional task. Phys Ther 1990; 788-798.

17. VanSant Ann F. Rising from a supine position to erect stance: description of adult movement and a developmental hypothesis. Phys Ther 1988;68:185-192.

18. Williams CE, Pearson PH. Physical therapy service in the developmental disabilities. by Charles C Thomas Publisher, 1972; 31-33.

19. Yokochi K, Yokochi M, Kodama K. Motor function of infants with spastic hemiplegia. brain \& development 1995; 17:42-8. 


\section{Appendix; Movement Pattern Descriptions (Marsala and VanSant, 1998) ${ }^{12}$}

\section{Upper-Extremity Movement Categories}

\section{1-Push and Reach to Bilateral Push}

one hand is placed on the support surface beside the pelvis. The other arm reaches across the body, and hand is placed on the surface. Both hands push against the surface to an extended elbow position. the arms are then lifted and used for balance.

\section{2-Push and Reach}

One or both arms are used to push against the support surface. If both arms are used, there is an asymmetry or asynchrony in the pushing action or a symmetrical push gives way to a single push pattern.

\section{3-Symmetrical Push}

Both hands are placed on the surface. Both hands push symmetrically against the surface prior to the point when the arms are lifted synchronously and used th assist with balance.

\section{4-symmetrical Reach}

The arms reach forward, leading the trunk, and are used as balance assists throughout the movement.

\section{5-Push and Reach Followed by Pushing on Leg}

One or both arms are used to push against the support surface or to reach forward. Pushing and reaching movements give way to a single arm push against the support surface. One ir both hands are placed on the knee, and then the arms are lifted and used for balance.

\section{6-Push and Reach to Bilateral Push Followed by Pushing on Leg}

One or both hands are placed on the supporting surface beside the pelvis. After an initial push, one arm reaches across the body and the hand is placed on the surface. Both hands push against the surface to an extended arm position. One or both hands are places on the knee, and then the arms are lifted and used for balance.

\section{Revised Axial Movement Categories}

\section{1-Full Rotation, Abdomen Down}

The head and trunk flex and rotate until the ventral surface of the trunk contacts the support surface. The pelvis is then elevated to or above the lev디 of the shoulder girdle. The back extends up to the vertical, with or without accompanying rotation of the trunk.

\section{2-Full Rotation, Abdomen Up}

The head and trunk flex and/or rotate until the ventral surface of the trunk faces, but does not contact, the support surface. The pelvis is then elevated to or above the level of the shoulder girdle. The back extends from this position up to the vertical, with or without accompanying rotation of the trunk.

\section{3-Partial Rotation}

Flexion and rotation bring the body to a side-facing position or beyond with the shoulders remaining above the level of the pelvis. The back extends up to the vertical, with or without accompanying rotation. 


\section{4-Forward With Rotation}

The head and trunk flex forward with or without a slight degree of rotation. Symmetrical flexion is then interrupted by rotation or extension with rotation. Flexion with slight rotation is corrected by counter-rotation in the opposite direction. One or more changes in the direction of the rotation occor. A front or slightly diagonal facing is achieved before the back extends to the vertical.

\section{5-Symmetrical}

The head and trunk move symmetrically forward past the vertical; the back then extends symmetrically to the upright position.

\section{Revised Lower-Extremity Movement Categories}

\section{1-Pike}

The legs are flexed toward the trunk and may be rotated to one side with knees or a and foot in contact both the ground. Both feet then contact the support surface. The legs are fully extended to a pike position. Slight flexion of the legs is followed by full extension during the rise.

\section{2-Pike-Jump to Squat}

The leg are flexed toward the trunk with both knees contacting the support surface. The feel are then placed in contact with the support surface while the legs remain flexed. Next the legs are fully extended to the pike position. Both feet are then lifted simultaneously off the support surface. The feet land back on the support surface in closer proximity to the hands, with the hips and knee flexing to a squat position. The legs are then extended during the rise.

\section{3-Kneel}

The legs are flexed toward the trunk and rotated to one side with both knees contacting the support surface. Half kneeling may be assumed, or a squat pattern. When the legs extend, one or more balance steps may be taken.

\section{4-Jump to Squat}

The legs are flexed and/or rotated to one side. Both legs are then lifted simultaneously off the support surface and may be de-rotated. The feet land back on the support surface with the hips and knees flexing to a squat or semi-squat position. The legs then extend to the vertical.

\section{5-Half Kneel}

Both legs are flexed toward the trunk as one or both legs rotated to one side. Either a kneeling or half-kneeling pattern is assumed. If kneeling occurs, one leg os then flexed forward to assume half kneeling. The forward leg pushes into extension as the opposite leg moves forward and extends.

\section{6-Asymmetrical/Wide-base Squat}

One or both legs are flexed toward the trunk, assuming an asymmetrical, crossed-leg, or wide-based squat. The legs push into an extended position. Crossing or asymmetries may be corrected during extension by stepping action.

\section{7-Narrow-Based Symmetrical Squat}

The leg are brought into flexion the heels approximation the buttocks in a narrow-based squat. Stepping action may be seen during assumption of the squat, or balance steps (or hops) may follow the symmetrical rise. 
